\title{
Catecholamine-induced Lipolysis in Adipose Tissue of the Elderly
}

Fredrik Lönnqvist, Björn Nyberg, * Hans Wahrenberg, and Peter Amer

Departments of Medicine and *Surgery, and the Research Center at Huddinge University Hospital, S-141 86 Huddinge, Sweden

\begin{abstract}
Age-dependent alterations in the effects of catecholamines on lipolysis were investigated in 25 young (21-35 yr) and 10 elderly (58-72 yr) healthy, nonobese subjects using isolated adipocytes obtained from abdominal subcutaneous tissue. Basal lipolysis was not affected by aging, while the rate of catecholamine-stimulated lipolysis was reduced by $50 \%$ in the elderly subjects $(P<0.005)$. To elucidate the mechanisms behind this phenomenon lipolysis was stimulated with agents that act at well-defined steps in the lipolytic cascade, from the receptor down to the final step: the activation of the protein kinase/ hormone-sensitive lipase complex. All agents stimulated lipolysis at a 50\% lower rate in elderly as compared with young subjects $(P<0.05$ or less). However, half-maximum effective concentrations of the lipolytic agents were similar in both groups. The antilipolytic effects of alpha 2 -adrenoceptor agonists were also the same in young and old subjects. Moreover, the stoichiometric properties of the beta- and alpha 2 -receptors did not change with increasing age. In vivo studies performed on the same individuals likewise demonstrated an impaired lipolytic responsiveness, with $50 \%$ lower plasma glycerol concentrations during exercise in the elderly subjects $(P<0.05)$, in spite of a normal rise in plasma norepinephrine. The plasma glycerol levels correlated strongly to the glycerol release caused by catecholamine-stimulated lipolysis in vitro in both young and elderly subjects $(r=0.8-0.9, P<0.001)$. In conclusion, a decreased activation of the hormone-sensitive lipase complex appears to be the mechanism underlying a blunted lipolytic response of fat cells to catecholamine stimulation in elderly subjects. This finding may, explain the age-dependent decreased lipolytic response to exercise in vivo. (J. Clin. Invest. 1990. 85:1614-1621.) fat cells • glycerol • adrenergic receptors $\bullet$ adenylate cyclase $\bullet$ exercise
\end{abstract}

\section{Introduction}

The ability of hormones, including catecholamines, to activate responses in a variety of tissues decreases with age (1-3). However, the mechanisms responsible for age-related alterations in hormone action are not clear. Catecholamines modulate a great number of biological responses, including lipid mobilization by means of adipose tissue lipolysis. In this respect catecholamines are the only hormones with a pronounced lipolytic effect on fat cells in adult man (4). Catecholamine action can

Address reprint requests to Dr. F. Lönnqvist, Department of Medicine, Huddinge Hospital, S-141 86 Huddinge, Sweden.

Received for publication 26 September 1989 and in revised form 20 December 1989.

J. Clin. Invest.

(C) The American Society for Clinical Investigation, Inc. 0021-9738/90/05/1614/08 \$2.00

Volume 85, May 1990, 1614-1621 be modulated at the target tissue level or by changes in the abundance of the hormones. The decreased catecholamine action in elderly subjects is apparently not related to the circulating catecholamine levels since increased levels of plasma norepinephrine in the elderly have been documented in several conditions (5). On the other hand, it is apparent that the action of catecholamines via adrenergic receptors in target tissues, such as the heart, the cardiovascular system, the kidneys and the fat tissue, is blunted in elderly subjects (6-10).

A large number of investigators have concluded that the beta-adrenergic responsiveness decreases with age (11-21). However, it is not known at what level in the catecholamine action these age-dependent changes are located. Decreased and normal number of beta-adrenergic receptors have been demonstrated in elderly subjects using human lymphocytes $(12,16,20,21)$. However, these cells are not targets for catecholamine action.

It is well established that catecholamine-induced lipolysis is reduced in fat cells of elderly subjects $(9,10)$. However, the mechanisms responsible for this change in hormone action are unknown. Several steps in catecholamine action have to be considered (22). These include the lipolytic beta-adrenoceptors, the antilipolytic alpha ${ }_{2}$-adrenoceptors, adenylate cyclase, G-proteins, phosphodiesterase and the final step in lipolysis activation: the protein kinase/hormone-sensitive lipase complex.

In the present study we have investigated the stepwise regulation of catecholamine-induced lipolysis in fat cells obtained from young and elderly nonobese, healthy men. The effects of agents acting at well-defined steps on catecholamine-induced lipolysis were investigated in isolated adipocytes. The stoichiometric properties of beta- and alpha ${ }_{2}$-adrenoceptors were also studied in intact adipocytes, using radioligand binding techniques. In addition, the plasma levels of glycerol and catecholamines at rest and during exercise were determined for comparison of lipolysis in vivo and in vitro between the age groups.

\section{Methods}

Subjects. The study comprised 35 men. Their clinical data are given in Table I. They were divided into two age groups; one older group with 10 subjects ranging from 58 to $72 \mathrm{yr}$ and one younger with 25 subjects ranging from 21 to $35 \mathrm{yr}$. Although all the men were of normal weight, the body mass index of the older group was slightly higher than in the younger group $(P<0.025)$. However, there was no difference between the two groups concerning the waist-to-hip ratio. The young men were healthy volunteers, while the older group consisted of men who were admitted to the hospital because of elective surgery for inguinal hernia. The latter subjects were in all other aspects healthy and were not on any medications.

After an overnight fast one subcutaneous fat specimen was excised from the infraumbilical region. Prilocaine chloride without vasoconstrictor (e.g., epinephrine) was used as the local anesthetic agent. It was administered in such a way that it did not influence the experiments on the excised adipose tissue (23). In the older group the specimen was excised at the beginning of surgery before the hernia operation. The 
biopsy and the hernia operation were performed under local anesthesia, which was administered as in the younger subjects.

It was not possible to perform all types of experiments on adipose tissue from the same donor in the younger group since, for ethical reasons only $2-4 \mathrm{~g}$ of adipose tissue could be excised. In the older group undergoing surgery it was, though, possible to perform the complete experimental program in each of the donors since 5-6 $\mathrm{g}$ of adipose tissue could be removed from these men. All subjects gave their informed consent and the study was approved by the Ethics Committee of Karolinska Institute.

In vivo study. About 2 mo after the excision of the fat specimens eight young and eight old participants underwent a new examination which was performed in the morning after an overnight fast. First a sampling cannula was inserted into the antecubital vein. After $20 \mathrm{~min}$ in the supine position blood samples for epinephrine, norepinephrine, and glycerol were drawn. Next the subjects rested $15 \mathrm{~min}$ more in the sitting position before the new samples were taken. Then, they exercised on a bicycle ergometer for $30 \mathrm{~min}$ at a load corresponding to two-thirds of their maximum working capacity. The plasma levels of glycerol, norepinephrine, and epinephrine were determined in blood samples obtained after 15 and $30 \mathrm{~min}$ of exercise as described previously (24).

Isolation of adipocytes and adipocyte measurements. Fat cells were isolated as described previously (25). The fat cell volume and the number of fat cells incubated were determined by direct microscopy measurements of isolated adipocytes, as described in detail previously (25).

Binding assays. As recently discussed in detail (24-26) total receptor number can be estimated from saturation experiments with labeled antagonists, whereas agonists recognize two states of the adrenoceptor, one with a high and one with a low affinity. Therefore, the adrenoceptor binding isotherms were determined using both agonists and antagonists. Intact adipocytes were incubated under steady-state conditions, as described in detail (24). Briefly, $\sim 20,000$ adipocytes were incubated in duplicate at $37^{\circ} \mathrm{C}$ in $1 \mathrm{ml}$ of Krebs-Ringer-phosphate (KRP) buffer (pH 7.4) containing bovine serum albumin (BSA) $5 \mathrm{~g} /$ liter, glucose ( $1 \mathrm{~g} /$ /iter), ascorbic acid $(0.1 \mathrm{~g} /$ /iter) plus radioligands with and without unlabeled adrenergic antagonist. Separation of cell-bound and free ligand was performed by filtration. The total number of available adrenergic binding sites on fat cells was estimated using $\left[{ }^{[25} \mathrm{I}\right]$ iodocyanopindolol $\left(\left[{ }^{125} \mathrm{I}\right] \mathrm{CYP}\right)$ as beta-adrenergic ligand and $\left[{ }^{3} \mathrm{H}\right]$ yohimbine as alpha ${ }_{2}$-adrenergic ligand. Complete saturation experiments were performed on fat cells from six individuals in the younger, and all 10 in the older group. In the beta-adrenoceptor experiments fat cells were incubated for $60 \mathrm{~min}$ with [ $\left.{ }^{125} \mathrm{I}\right] \mathrm{CYP}$ in eight increasing concentrations from 15 to $1,000 \mathrm{pmol} / \mathrm{liter}$. Nonspecific binding $(40 \%)$ was determined from parallel incubations in the presence of $0.1 \mu \mathrm{mol} / \mathrm{liter}$ of propranolol. In the alpha ${ }_{2}$-adrenoceptor experiments fat cells were incubated for 15 min with $\left[{ }^{3} \mathrm{H}\right]$ yohimbine in eight concentrations ranging from 0.3 to $20 \mathrm{nmol} /$ liter of phentolamine. The total number of binding sites $\left(B_{\max }\right)$ and affinity constants $\left(K_{\mathrm{d}}\right)$ for the radioligands was measured by Scatchard's method.

In competitive experiments with unlabeled agonists half of the amount of adipocytes mentioned above was incubated in a final volume of $0.5 \mathrm{ml}$. In the beta-adrenergic experiments adipocytes were incubated with $100 \mathrm{pmol} / \mathrm{liter}$ of [ $\left.{ }^{125} \mathrm{I}\right] \mathrm{CYP}$ for $60 \mathrm{~min}$ in the presence or absence of 12 different concentrations of isoprenaline ranging from $10^{-11}$ to $10^{-4} \mathrm{~mol} /$ liter. In the alpha ${ }_{2}$-adrenoceptor assay $5 \mathrm{nmol} /$ liter of $\left[{ }^{3} \mathrm{H}\right]$ yohimbine was incubated as above for $15 \mathrm{~min}$ in the presence or the absence of 12 different concentrations of clonidine, ranging from $10^{-12}$ to $10^{-4} \mathrm{~mol} /$ liter. Nonspecific binding was determined at the highest concentration $\left(10^{-4} \mathrm{~mol} /\right.$ liter $)$ of the agonist and was not different from nonspecific binding determined with antagonists. The dis-

1. Abbreviations used in this paper: ADA, adenosine deaminase; $\mathrm{CYP}$, iodocy-anopindolol; KRP, Krebs-Ringer phosphate; PIA, $N^{6}$-phenylisopropyl-adenosine. placement curves were always shallow. They were analyzed by a computer-assisted modeling technique (27). From these data the dissociation constants for high-affinity $\left(K_{\mathrm{h}}\right)$ and low-affinity $\left(K_{1}\right)$ sites and the proportion of high $\left(R_{\mathrm{h}}\right)$ and low $\left(R_{1}\right)$ affinity binding sites were calculated.

Lipolysis assay. The assay has been described in detail (25). Briefly, $\sim 2,000$ adipocytes were incubated in duplicate with air as the gas phase in $0.2 \mathrm{ml}$ of a medium of the composition as mentioned above, except that the albumin concentration was increased at $40 \mathrm{~g} /$ liter. At the end of the incubation period an aliquot of the medium was taken for the determination of glycerol by a sensitive automatic kinetic bioluminescent method (28). In one set of experiments, adipocytes were incubated for $2 \mathrm{~h}$ with various concentrations of $(a)$ noradrenaline (nonselective beta- and alpha-agonist), with and without $100 \mu \mathrm{mol} /$ liter of yohimbine (alpha ${ }_{2}$-adrenergic antagonist), $(b)$ isoprenaline (nonselective beta-adrenergic agonist), (c) clonidine (selective alpha $2^{-}$ agonist), $(d)$ forskolin (activator of adenylate cyclase), $(e)$ enprofylline (inhibitor of phosphodiesterase), $(f)$ dibuturyl-cyclic AMP (a phophodiesterase-resistant stimulator of protein kinase/hormone-sensitive lipase) and $(g) \mathrm{N}^{6}$-phenylisopropyl-adenosine (PIA, adenosine analogue). In some experiments the medium was supplemented with 1 $\mathrm{U} / \mathrm{ml}$ of adenosine deaminase (ADA) to remove endogenous adenosine. In another set of experiments the lipolytic effect of cholera toxin (which ADP-ribosylates the stimulatory GTP-binding protein Gs) and pertussis toxin (which stimulates adenylate cyclase through ADP-ribosylation of the inhibitory GTP-binding protein Gi) was investigated. Both toxins were activated before use (24-26). Fat cells were incubated for 2 and $3 \mathrm{~h}$ with or without $10 \mu \mathrm{g} / \mathrm{ml}$ of cholera toxin or $1 \mu \mathrm{g} / \mathrm{ml}$ of pertussis toxin. In the toxin experiments, the difference in glycerol release between the second and third hour of incubation was calculated. The responsiveness, i.e., the maximal effect on lipolysis, was calculated as the difference between basal glycerol release and glycerol release at the maximum effective concentration of the lipolytic or antilipolytic agent. The concentration of adrenergic agonist that produced a half-maximum effect $\left(\mathrm{ED}_{50}\right)$ was calculated by logistic conversion of the dose-effect curves.

Chemicals. Dialyzed bovine serum albumin (fraction V) was purchased from Armour (Eastbourne, UK). [ $\left.{ }^{3} \mathrm{H}\right]$ Yohimbine $(85 \mathrm{Ci} /$ $\mathrm{mmol})$ and [ $\left.{ }^{125} \mathrm{I}\right] \mathrm{CYP}(2200 \mathrm{Ci} / \mathrm{mmol})$ were purchased from New England Nuclear (Boston, MA). Propranolol was kindly donated by Hässle AB (Gothenburg, Sweden), phentolamine by Ciba Geigy (Basel, Switzerland) and clonidine by Boehringer-Ingelheim (Rhein, FDR). Pertussis toxin was obtained from List Biological Laboratories (Campbell, CA). All other agents were purchased from Sigma Chemical Co. (St. Louis, MO) and were of highest analytical grade.

Statistical methods. The values presented are the means \pm standard error of the means (SE). Regression analysis, two-way analysis of variance for repeated measures (ANOVA) and the Student's unpaired $t$ tests were used for the statistical comparison of the results.

\section{Results}

Fat cell volume. The fat cell volumes were similar in the elderly and the young group (Table I). As the adipocyte volumes were not significantly different in the two groups all fat cell data were expressed per number of fat cells.

Lipolysis in isolated fat cells. The basal rate of lipolysis was similar in young and elderly subjects $(4.43 \pm 0.66$ vs. $3.73 \pm 0.82$ $\mu \mathrm{mol}$ glycerol $/ 2 \mathrm{~h}$ per $10^{7}$ cells).

Fig. 1 shows the results with catecholamine-stimulated lipolysis. When lipolysis was stimulated selectively through beta-adrenoceptors with isoprenaline or norepinephrine plus yohimbine, the maximum stimulation of lipolysis (i.e., responsiveness) was markedly and significantly decreased in the older group (Table II). A distinct difference $(\sim 50 \%)$ in lipolytic effect was seen at all concentrations of the catecholamines. The two catecholamines increased lipolysis 8-10 times in the 
Table I. Clinical Data in 10 Elderly and 25 Young Men

\begin{tabular}{lccccc}
\hline Subjects & Age & $\begin{array}{c}\text { Body mass } \\
\text { index }\end{array}$ & $\begin{array}{c}\text { Waist-to-hip } \\
\text { ratio }\end{array}$ & $\begin{array}{c}\text { Fat cell } \\
\text { volume }\end{array}$ & $\begin{array}{c}\text { Fat cell } \\
\text { diameter }\end{array}$ \\
\hline & & & & $p l$ & $\mu m$ \\
Young & $29 \pm 1$ & $22.6 \pm 0.5$ & $0.94 \pm 0.02$ & $426 \pm 29$ & $87.4 \pm 3.5$ \\
Elderly & $65 \pm 2$ & $24.6 \pm 0.5$ & $0.96 \pm 0.01$ & $452 \pm 31$ & $91.4 \pm 1.9$ \\
& $P<0.001$ & $P \leq 0.025$ & NS & NS & NS \\
\hline
\end{tabular}

Fat cell volume and diameter were determined on isolated fat cells obtained from the abdominal region. $P$ denotes the result of statistical comparison using Student's two-tailed $t$ test.

young men but only 5-6 times in the older ones. On the other hand, no difference in catecholamine sensitivity was seen between the groups. Nor did individual $\mathrm{ED}_{50}$-values for lipolysis stimulated with isoprenaline and norepinephrine plus yohimbine differ between the two groups (Table II). Since norepinephrine stimulates both the beta- and the alpha-receptors, the lipolytic response to norepinephrine alone was lower than that obtained with pure beta-receptor stimulation. The difference in norepinephrine-induced lipolysis between young and older men was nevertheless clearly visible $(\sim 50 \%)$, with maximal responses four to five times as compared to three times higher than basal lipolysis. All three dose-response curves were statistically different from one another in all concentrations $(P$ $<0.05-0.005$ ).

In uncharted experiments ADA was added to the incubation medium to remove adenosine. ADA increased the basal rate of lipolysis by $100 \%(P<0.01)$. However, there was no difference in ADA-induced lipolysis between the two groups. Moreover, the enzyme did not affect the difference in stimulated lipolysis between the two groups that was seen after the addition of isoprenaline or norepinephrine. This indicates that adenosine has no major effects on stimulated lipolysis in our incubation system.

The effects of agents that stimulate lipolysis at levels distal to the beta-adrenoceptor are shown in Fig. 2. Cholera toxin and pertussis toxin, added at maximum effective concentra- tions, stimulated lipolysis less effectively in the elderly subjects. The difference was about $50 \%(P<0.05-0.01)$. The same was true concerning lipolysis stimulated with forskolin, enprofylline and dibutyryl cyclic AMP. The difference between these agents. The difference in responsiveness between young and elderly subjects was in the same order of magnitude $(\sim 50 \%)$ regardless at which step lipolysis was selectively activated in the cyclic AMP system. There was no change in sensitivity to forskolin, enprofylline, or dibutyryl cyclic AMP with increasing age. The dose-response curves differed at all concentrations between the two groups.

To examine whether there was an age-dependent change in alpha ${ }_{2}$-adrenoceptor effect, adenylate cyclase inhibition experiments were conducted using the pure alpha ${ }_{2}$-agonist clonidine and the adenosine receptor agonist PIA (Fig. 3). Clonidine and PIA inhibited basal lipolysis in a dose-dependent way. At respective maximum effective concentrations clonidine and PIA almost completely inhibited basal lipolysis in both groups (i.e., $\sim 85 \%$ inhibition). Since basal lipolysis was slightly higher in the younger men the effect of the inhibition was expressed as a percentage of the maximum response. No difference in sensitivity was seen between the two groups as regards clonidine, the mean dose-response curves for young and elderly were almost identical if ADA was present or not (data not shown). The mean $\mathrm{ED}_{50}$-values were 790 and $560 \mathrm{pmol} / \mathrm{liter}$ in young and elderly men, respectively. However, there was a 45 -fold decrease in PIA sensitivity in older men as evidenced by the mean dose-response curves and the individual $\mathrm{ED}_{50}$ values. The latter values were $7 \pm 6 \mathrm{pmol} /$ liter in younger and $316 \pm 214$ $\mathrm{pmol} /$ liter in elderly men $(P<0.025)$.

Radioligand binding. Antagonist binding data for $\left[{ }^{125} \mathrm{I}\right]-$ CYP and $\left[{ }^{3} \mathrm{H}\right]$ yohimbine are given in Table III. Scatchard analysis data revealed that both radioligands bound to a single homogeneous class of binding sites. As indicated by the computerized calculations of $B_{\max }$ and $K_{\mathrm{d}}$, neither beta- and alpha ${ }_{2}$-adrenoceptor number nor radioligand receptor affinity differed between the two groups.

The competition-inhibition data are shown in Table IV. The results of agonist interactions with adrenergic receptors showed that both isoprenaline and clonidine competed with $\left[{ }^{125} \mathrm{I}\right] \mathrm{CYP}$ and $\left[{ }^{3} \mathrm{H}\right]$ yohimbine, respectively, in a dose-depen-
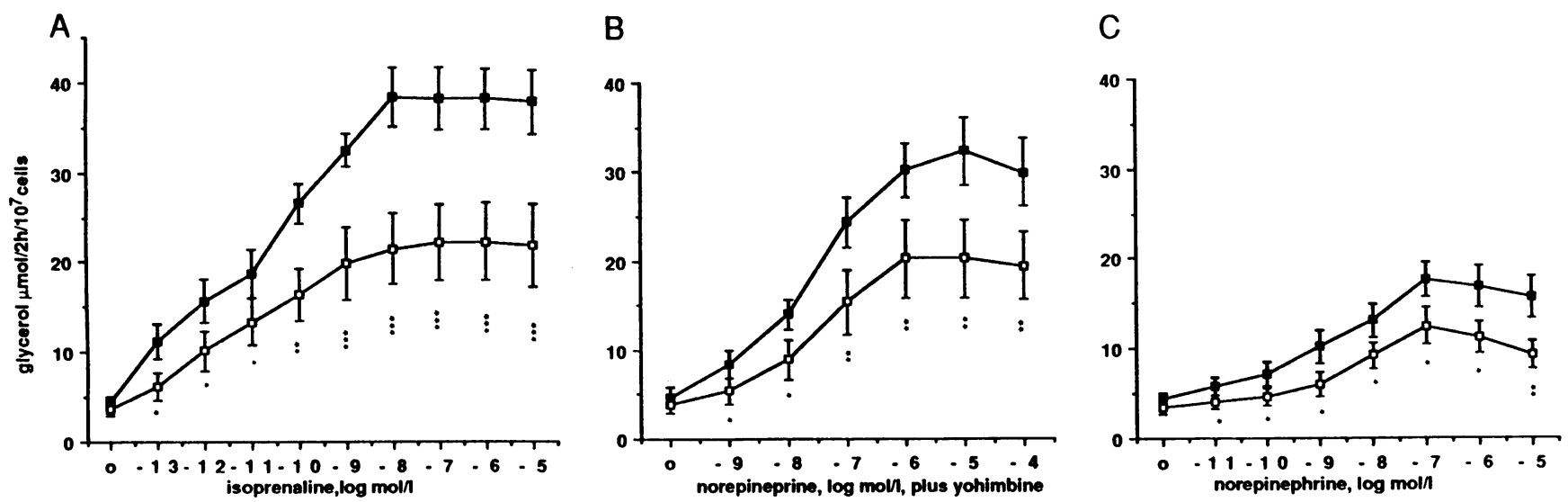

Figure 1. Lipolytic effects of catecholamines in isolated fat cells. Comparison of glycerol release induced by increasing concentrations of $(A)$ isoprenaline, $(B)$ norepinephrine plus $10^{-4} \mathrm{~mol} /$ liter of yohimbine and $(C)$ norepinephrine in 18 young (solid symbols) and 10 older (open sym$b o l s)$ men. Further details are given in Methods. Values are means \pm SE. The values were statistically compared using the Student's $t$ test, $* P$ $<0.05 ; * * P<0.025 ; * * * P<0.005$. 
Table II. Sensitivity and Responsiveness of the Lipolytic Effect of Catecholamines

\begin{tabular}{|c|c|c|c|c|}
\hline Subjects & Isoprenaline $\mathrm{ED}_{\mathbf{5 0}}$ & Responsiveness & $\begin{array}{l}\text { Norepinephrine plus } \\
\text { yohimbine } E D_{s_{0}}\end{array}$ & Responsiveness \\
\hline & pmol/liter & glycerol $\mu \mathrm{mol} / 2$ h per $10^{7}$ cells & nmol/liter & glycerol $\mu \mathrm{mol} / 2 \mathrm{~h}$ per $10^{7} \mathrm{cells}$ \\
\hline Young & $9.1 \pm 7.0$ & $39.2 \pm 3.5(17)$ & $17.0 \pm 10.7$ & $33.8 \pm 4.7(12)$ \\
\hline Elderly & $26.9 \pm 17.2$ & $23.2 \pm 4.5(10)$ & $38.9 \pm 11.7$ & $21.5 \pm 4.1(10)$ \\
\hline$P$ & NS & $\leq 0.005$ & NS & $\leq 0.025$ \\
\hline
\end{tabular}

Lipolytic responsiveness to catecholamines was calculated for each individual as the glycerol release at maximum effective concentration and expressed as $\mu \mathrm{mol} / 2 \mathrm{~h}$ per $10^{7}$ cells. Lipolytic sensitivity to catecholamines was expressed as the concentration of catecholamine giving a halfmaximum effect $\left(\mathrm{ED}_{50}\right)$. Number of experiments are shown in brackets. Values are means $\pm \mathrm{SE}$. The Student's unpaired two-tailed $t$ test was used for the statistical comparison. $P$ denotes the level of significance. NS, not significant.

dent way, giving shallow and complex curves with low Hill coefficients, which indicated a two-affinity state of the respective receptors. About $30 \%$ of the beta-receptors and $40 \%$ of the alpha $_{2}$-receptors were in the high-affinity state in both the young and the older subjects. Moreover, the affinity constants for the beta- and alpha $a_{2}$-adrenoceptors did not differ significantly between the age groups.

In vivo results. The in vivo results are shown in Fig. 4. Exercise induced a gradual increase in the plasma levels of norepinephrine, epinephrine, and glycerol in both groups. The older men had significantly higher levels of plasma norepinephrine at supine rest $(3.5 \pm 0.8$ vs. $1.7 \pm 0.3 \mathrm{nmol} / \mathrm{liter}, P$ $<0.01)$. The difference between the groups was also noted with the subject seated on the bicycle $(4.9 \pm 1.0$ vs. $3.3 \pm 0.3 ; P$ $<0.01$ ) but disappeared totally during physical exercise. There
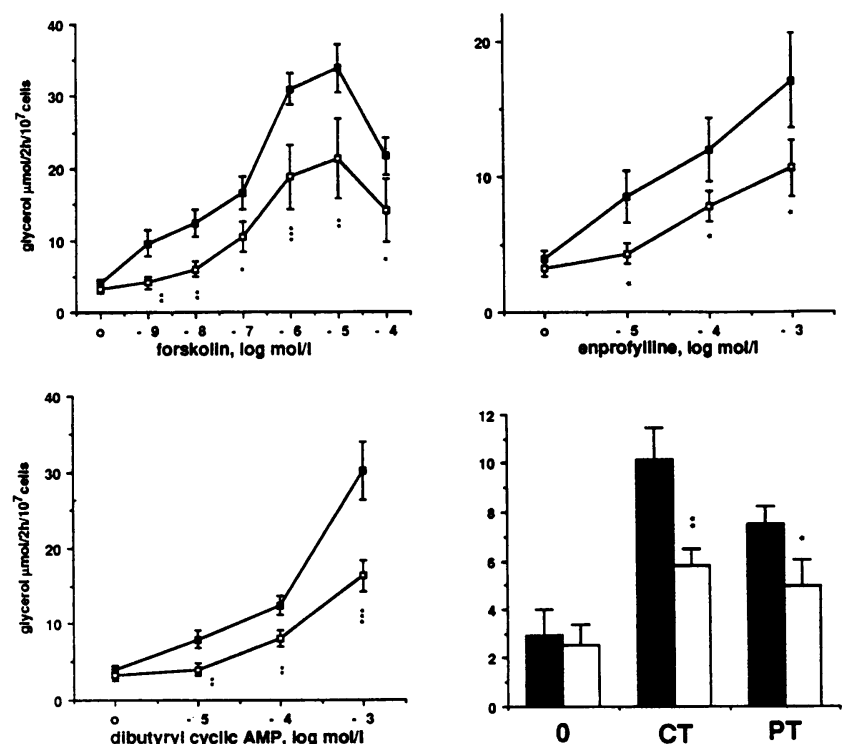

Figure 2. Stimulation of lipolysis at steps beyond the beta-adrenoceptor. Fat cells were incubated with or without forskolin, enprofyllin, dibutyryl cyclic AMP, cholera toxin (CT; $10 \mu \mathrm{g} / \mathrm{ml}$ ) or pertussis toxin (PT; $1 \mu \mathrm{g} / \mathrm{ml}$ ). Basal lipolysis is indicated with 0 . The lipolytic effects in isolated fat cells from 16 young (solid symbols) and 10 older men (open symbols) were compared. Further details are given in Methods. Values are means \pm SE. $* P<0.05 ; * * P<0.025 ; * * * P$ $<0.005$. 1, liter. was no difference in the plasma epinephrine levels between the two groups at rest. However, during exercise, the increase in plasma epinephrine was less pronounced in the older subjects. At $30 \mathrm{~min}$ of exercise the plasma levels were almost twice as high in the young subjects as in the older ones $(1.04 \pm 0.12$, respectively, $0.55 \pm 0.19 \mathrm{nmol} / \mathrm{liter} ; P<0.005$ ).

At rest the plasma glycerol level was about the same in both groups. During exercise, however, the glycerol level was significantly lower in the older group, $P<0.05$, indicating a decreased lipolytic response to exercise. The lipolytic response obtained with isoprenaline or norepinephrine plus yohimbine in vitro correlated significantly with the plasma glycerol levels in the same individuals at $30 \mathrm{~min}$ of exercise $(r=0.84$ and $r$ $=0.88 ; P<0.001$ ) (Fig. 5).

Results of alternative calculations. The lipolysis results were expressed per number of cells. The differences between young and elderly subjects persisted when the cell surface area was used instead as the denominator. The statistical values presented were determined by the Student's $t$ test. The same levels of significance was obtained when analysis of variance was used as the statistical method.

\section{Discussion}

In the present paper the mechanisms underlying decreases in catecholamine-induced lipolysis with advancing age were ex-
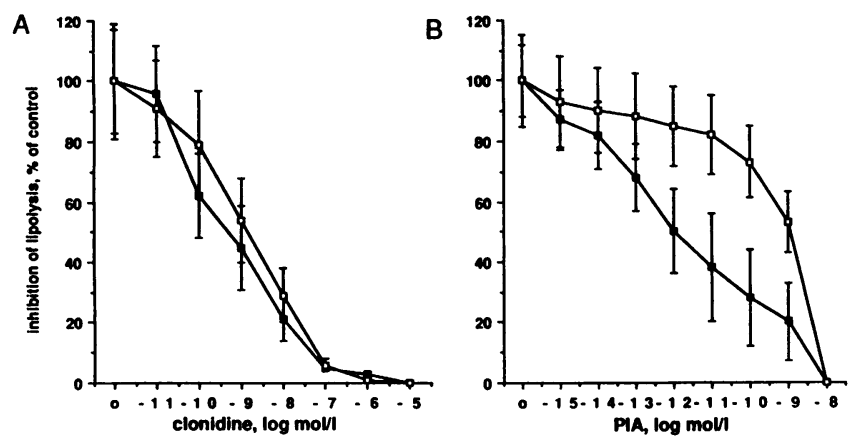

Figure 3. Antilipolytic effect of the alpha ${ }_{2}$-adrenergic agonist clonidine or the adenosine analogue PIA in 16 young (solid symbols) and 9 elderly subjects (open symbols). The antilipolytic effect was expressed as a percentage of the maximum inhibition of basal lipolysis. Isolated fat cells were incubated as described in Methods. Adenosine deaminase $(1 \mathrm{U} / \mathrm{ml})$ was added to the incubation medium in the experiments with PIA. Values are means \pm SE. l, liter. 
Table III. Specific Binding of Radioactive Betaand Alpha ${ }_{2}$-antagonists in Young and Elderly Men

\begin{tabular}{lll}
\hline Results from Scatchard analyses & Young & Elderly \\
\hline Beta-sites [ ${ }^{125}$ I]cyanopindolol & & \\
$K_{\mathrm{d}}($ pmol/liter $)$ & $47.7 \pm 9.3$ & $38.5 \pm 7.1$ \\
$\mathrm{~B}_{\max }\left(p m o l / 10^{7}\right.$ cells $)$ & $0.75 \pm 0.07$ & $0.70 \pm 0.10$ \\
Alpha $_{2}$-sites $\left[{ }^{3} \mathrm{H}\right]$ yohimbine & & \\
$K_{\mathrm{d}}(\mathrm{nmol} / \mathrm{liter})$ & $4.4 \pm 0.8$ & $4.9 \pm 0.9$ \\
$\mathrm{~B}_{\max }\left(\mathrm{pmol} / 10^{7}\right.$ cells $)$ & $3.4 \pm 0.4$ & $4.7 \pm 1.3$ \\
\hline
\end{tabular}

Results of Scatchard analyses of complete saturation experiments of $\left[{ }^{125} \mathrm{I}\right] \mathrm{CYP}$ and $\left[{ }^{3} \mathrm{H}\right]$ yohimbine binding. $B_{\max }$ and dissociation constants for the radioligands were determined from abdominal adipocytes obtained from 6 young and 10 elderly men. All values are means \pm SE. Student's unpaired $t$ test was used for statistical comparison. No significant differences were seen between the two age groups.

amined in human fat cells by studying the effects of drugs acting selectively at different levels of the lipolytic cascade and by radioligand experiments. The lipolytic response to catecholamines was markedly impaired in elderly subjects, which confirms earlier data $(9,10)$. This decrease in catecholamine effciency with aging is in line with previous findings in other tissues $(6-8,11)$. We suggest that the reason for the impairment of glycerol release after catecholamine stimulation in elderly subjects is decreased activation of the last step in the lipolytic cascade, the hormone-sensitive lipase complex. The best evidence for this opinion is that all of the selectively acting lipolytic agents used induced $\sim 50 \%$ lower responses in elderly subjects as compared with young subjects. Thus fat cell lipolysis in the elderly subjects was blunted to the same extent regardless of the step at which lipolysis was activated. A general defect in the hormone-sensitive lipase is not likely since the

Table IV. Beta- and Alpha ${ }_{2}$-adrenoceptor Affinities for Isoprenaline and Clonidine, Respectively, and the Proportions of Receptors in a High-affinity State in Young and Elderly Men

\begin{tabular}{lcc}
\hline \multicolumn{1}{c}{ Results of competition-inhibition experiments } & Young & Elderly \\
\hline Beta-sites [ $\left.{ }^{125} \mathrm{I}\right]$ cyanopindolol-isoprenaline & & \\
$\quad K_{\mathrm{h}}(\mathrm{nmol} /$ liter $)$ & $3.6 \pm 3.3$ & $2.8 \pm 1.8$ \\
$\mathrm{~K}_{\mathrm{l}}(\mu \mathrm{mol} /$ liter $)$ & $4.8 \pm 2.1$ & $2.7 \pm 0.9$ \\
$\% R_{\mathrm{h}}$ & $32 \pm 4$ & $34 \pm 3$ \\
Alpha & & \\
$K_{\mathrm{h}}$-sites $\left[{ }^{3} \mathrm{H} \mathrm{Hol} /\right.$ liter $)$ & & \\
$\mathrm{K}_{\mathrm{l}}(\mu \mathrm{mol} /$ liter $)$ & $2.2 \pm 1.7$ & $1.6 \pm 0.9$ \\
$\% R_{\mathrm{h}}$ & $1.3 \pm 0.9$ & $0.9 \pm 0.2$ \\
& $39 \pm 6$ & $38 \pm 4$ \\
\hline
\end{tabular}

Results of competition-inhibition experiments analyzed by a computer-iterative curve fitting to a model for two classes of non-interacting binding sites, which give the dissociation constants for high$\left(K_{\mathrm{h}}\right)$ and low- $\left(K_{1}\right)$ affinity states and the percentage of receptors in a high-affinity state $\left(\% R_{\mathrm{h}}\right)$. Adipocytes were obtained from 6 young and 10 elderly men and were incubated with $\left[{ }^{125} \mathrm{I}\right]$ cyanopindolol or $\left[{ }^{3} \mathrm{H}\right]$ yohimbine as described in the text. All values are means $\pm \mathrm{SE}$. Student's unpaired $t$ test was used for statistical comparison. No significant differences were seen between the two groups. basal unstimulated lipolysis was the same in the two age groups, still a decrease in the amount of available enzyme complexes can not be excluded.

In this study we did not find any evidence of alterations in the stoichiometric properties of beta-adrenoceptor or alpha ${ }_{2}$ adrenoceptors. The receptor numbers, the receptor affinities as well as the proportion of high-affinity receptors remained unchanged with age for both receptor types. Furthermore, the lipolysis experiments show that the $\mathrm{ED}_{50}$-values for catecholamines were almost identical in the two groups, which further supports the thesis that the catecholamine sensitivity remains unchanged with advancing age. Moreover, the responsiveness of catecholamine inhibition via alpha $a_{2}$-adrenoceptors was similar in young and old subjects. Thus, the properties of alpha adrenoceptors and beta-adrenoceptors in human fat cells appear not to be influenced by advancing age.

To obtain steady state conditions the present investigations were performed in the morning after an overnight fast. It is known that fasting sometimes has an inhibitory effect on catecholamine-induced lipolysis in human fat cells (see reference 4 for a review). Theoretically, such an effect may be augmented in elderly subjects. For several reasons, however, it is not likely that the observed decrease in lipolytic activity in elderly subjects is a fasting-mediated effect. First, the effects of fasting are only observed after prolonged caloric deprivation and not after an overnight fast. Second, they involve alpha ${ }_{2}$-adrenoceptor mediated mechanisms, which were normal in elderly. Third, they are only observed in peripheral adipose tissue and not in the abdominal fat depot, which was investigated presently.

The proposed mechanism underlying the age-related impairment of catecholamine-induced lipolysis in elderly humans is different from previous findings in rat adipose tissue. In the rat, the impairment has been thought to be caused by an increased phosphodiesterase activity $(13,29,30)$ or a more pronounced antilipolytic effect of adenosine $(31,32)$. Nevertheless, a postreceptor defect has also been proposed (33). In this study we found differences in lipolytic response between young and elderly subjects when we used both the selective phosphodiesterase inhibitor enprofylline and the phosphodiesterase resistant cyclic AMP analogue dibutyryl cyclic AMP. Although the latter agent may stimulate phosphodiesterase and thereby reduce the endogenous cyclic AMP content it is probably of minor importance for lipolysis activation. Dibutyryl cyclic AMP is not metabolized by phosphodiesterase and the highest concentration of the agent used in the present experiments ( $1 \mathrm{mmol} /$ liter $)$ is most likely sufficient to produce maximum lipolysis activation. This speaks against change in phosphodiesterase as a major cause of the blunting of lipolysis with advancing age, nor did we find any differences between young and elderly subjects in basal or stimulated glycerol release after the addition of ADA and the antilipolytic action of the adenosine analogue PIA was reduced in the elderly subjects. This argues strongly against adenosine playing a role in impaired lipolysis in the elderly. The mechanisms underlying age-associated changes in lipolysis are furthermore obviously completely different from those in early childhood. In the latter group receptor-mediated changes concerning the alpha ${ }_{2}$ - and TSH-receptors are responsible for the developmental increase in lipolytic capacity $(34,35)$.

The effects of exercise on plasma glycerol were significantly less pronounced in elderly subjects, which indicated a decreased lipolytic response also in vivo. The plasma norepi- 

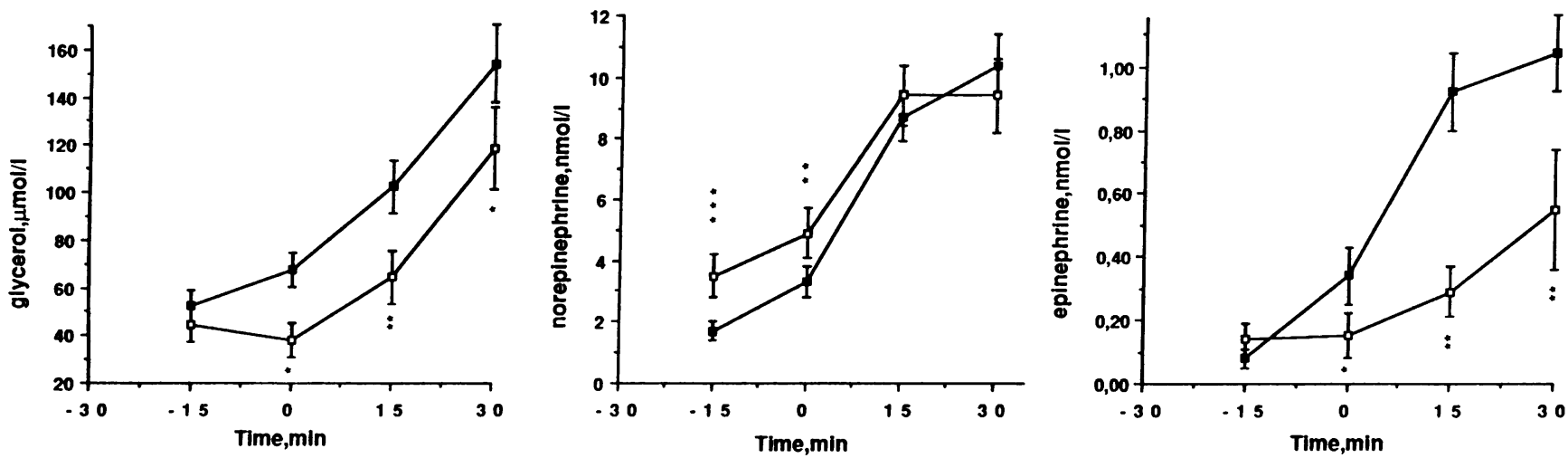

Figure 4. In vivo effects of exercise in eight young (solid symbols) and eight elderly men (open symbols). Plasma levels of glycerol, epinephrine, and norepinephrine were determined $15 \mathrm{~min}$ before exercise at rest in the supine position $(-15)$, sitting just before starting $(0)$ and after 15 and $30 \mathrm{~min}$ of exercise (see Methods). Values are means \pm SE. $* P<0.05 ; * * P<0.025 ; * * * P<0.005$. 1, liter.

nephrine levels, mirroring the total sympathetic system activity were, on the other hand, increased compared with the young subjects at rest. This confirms earlier studies (5). However, the difference in plasma norepinephrine at rest between young and elderly, disappeared completely with exercise. Consequently, the decrease in lipolytic response in the elderly is not explained by altered plasma norepinephrine concentrations. In contrast to norepinephrine, the plasma epinephrine concentrations were equal in the two groups at rest, while the response to exercise was much less pronounced in the elderly. This finding may explain the blunted lipolytic response to exercise in vivo with advancing age. However, the plasma epinephrine level mirrors the adreno-medullary sympathetic nervous system, which is thought to be less important for lipolysis than the more generally spread norepinephrine-regulated sympathetic system (36). Therefore, it is tempting to speculate that the cellular postreceptor defect observed in vitro may be the major mechanism underlying the impaired lipolytic response to exercise in elderly subjects. This hypothesis is further supported by the present finding of a strong correlation $(r>0.8)$ between the glycerol release after catecholamine stimulation of lipolysis in vitro and the plasma glycerol levels during exercise. However, it is always important to be cautious with extrapolations of in vitro data to in vivo conditions. In addition, circulatory factors, or other local lipolysis factors besides catecholamines and adenosine may to an unknown extent modulate lipolysis in our elderly subjects. It is also possible that the role of insulin in modulating catecholamine-induced lipolysis may be influenced by advancing age. Insulin is perhaps the most powerful hormone controlling lipolysis in man (37). It is possible that rising plasma catecholamines during exercise act in part by inhibition of insulin release which, in turn, leads to an
A

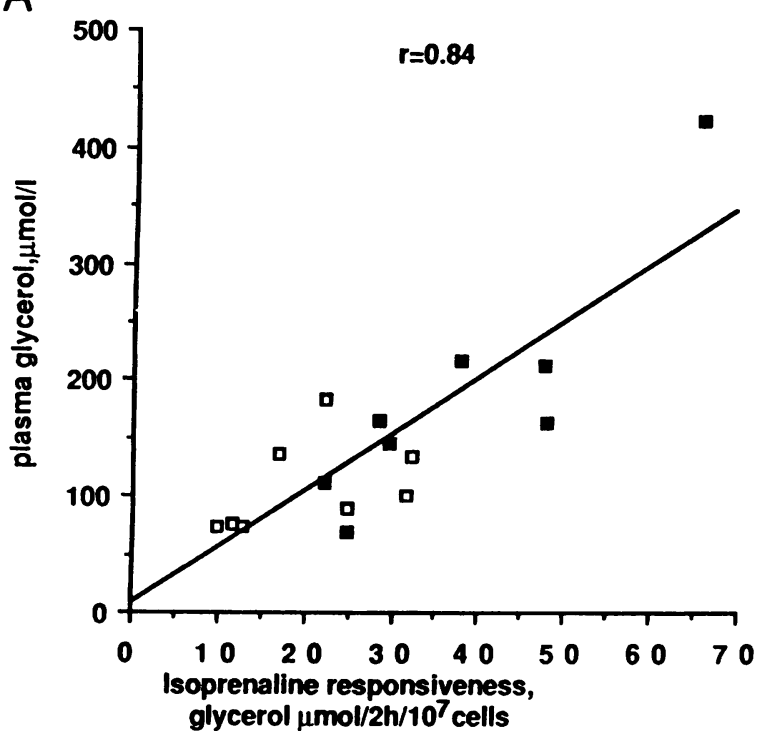

B

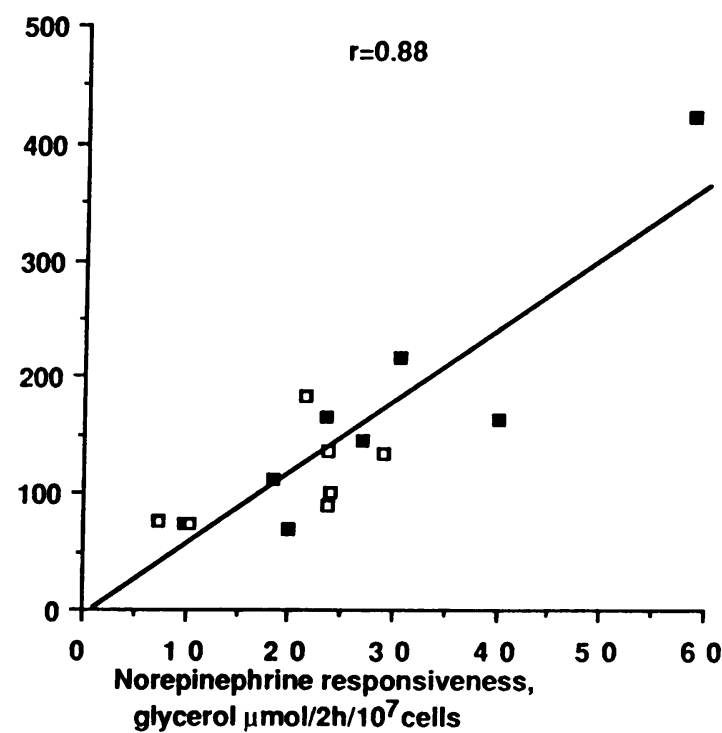

Figure 5. Relationship between the in vitro glycerol release at maximum effective concentrations of $(A)$ isoprenaline, $(B)$ norepinephrine plus $0.1 \mathrm{mmol} /$ liter of yohimbine, and the plasma glycerol concentrations in the same individuals after 30 min of submaximal work on a bicycle ergometer. Eight young (closed symbols) and eight elderly men (open symbols) participated in the exercise part of the study. The relationship between the two parameters was tested by linear regression analysis. $(A)$ Isoprenaline $(r=0.84, P<0.005)$. (B) Norepinephrine plus yohimbine $(r=0.88, P<0.001) .1$, liter. 
increase in lipolytic activity. For several reasons, however, insulin probably plays a minor role for the differences in lipolysis in vivo between young and elderly. First, there is only a minimal change in the plasma insulin concentration during the present type of exercise (38). Secondly, the antilipolytic effect of insulin is reduced in elderly subjects (39).

Catecholamine-induced lipolysis in fat cells is secondary to a rise in cyclic AMP production after the interaction between the hormone-receptor complex and the adenylate cyclase system (22). It is well established that there is a nonlinear relationship between cyclic AMP accumulation and lipolysis activation. In fat cells (see reference 22 for a recent review) a moderate rise in cyclic AMP is associated with maximal or near maximal increase in glycerol release, whereas larger increases in the nucleotide lead to no or minimal further increases in glycerol release. This suggests that the rate-limiting step in the lipolytic cascade is the hormone sensitive lipase complex and supports our conclusion that a reduced activity of this complex is the major mechanism behind the blunted lipolysis in elderly.

In theory, the higher norepinephrine levels in plasma of the elderly may have caused downregulation of the postreceptor cascade during exercise. It is, however, unlikely that such a mechanism is operating in these individuals. We have previously shown that the present type of exercise experiments cause increased catecholamine-induced lipolysis in fat cells of younger subjects because of upregulation of the postadrenoceptor cascade (38). If the opposite mechanism is present in elderly we would not have found an identical correlation between lipolysis in vitro and in vivo in both groups (Fig. 5).

In summary, the present results suggest that there is an impaired lipolytic response to catecholamines with advancing age in human fat cells. This may be due to a defective activation of the hormone-sensitive lipase complex in fat cells, since catecholamine receptors in the adipocytes are not altered by advancing age. Moreover, the lipolytic response to exercise is also reduced in elderly subjects which, to some extent, can be attributed to a diminished intracellular activation of lipolysis in fat cells.

\section{Acknowledgments}

This study was supported by grants from the Swedish Medical Research Council (19X-1034), the Karolinska Institute, the Swedish Medical Association, the Swedish Diabetes Association, and the Foundations of Groschinsky and Old Female Servants.

\section{References}

1. Roth, G. S. 1979. Hormone action during aging; alterations and mechanisms. Mech. Ageing Dev. 9:497-514.

2. Goldstein, S. 1979. Senescence. In Endocrinology. L. J. de Groot, G. F. Cahill, L. Martini, D. H. Nelson, W. D. Odell, J. T. Potts, E. Steinberger, and A. I. Winegrad, editors. Vol. 3. Grune \& Stratton. New York. 2001-2025.

3. Abrass, I. B., J. L. Davis, and P. J. Scarpace. 1982. Isoproterenol responsiveness and myocardial beta adrenergic receptors in young and old rats. J. Gerontol. 37:156-160.

4. Arner, P. 1988. Control of lipolysis and its relevance to development of obesity in man. Diabetes/Metabolism Rev. 4:507-515.

5. Cutler, R. N., and J. E. Hodes. 1983. Assessing the noradrenergic system in normal aging: A review of methodology. Exp. Ageing Res. 9:123-127.

6. Fleisch, J. H. 1981. Age-related decrease in beta adrenoceptor activity of the cardiovascular system. Trends Pharmacol. Sci. 2:337339.

7. Bühler, F. R., W. Kiowski, P. van Brummelen P., F. W. Amann, O. Bertel, R. Landman, B. E. Lütold, and P. Bolli. 1980. Plasma catecholamines and cardiac, renal and peripheral vascular adrenoceptor-mediated responses in different age groups of normal and hypertensive subjects. Clin. Exp. Hypertens. 2:409-426.

8. Pfeifer, M. A., C. R. Weinberg, D. Cook, J. D. Best, A. Reenan, and J. B. Halter. 1983. Differential changes of autonomic nervous system functions with age in man. Am. J. Med. 75:249-258.

9. Östman, J., S. Efendic, and P. Arner. 1969. Catecholamine metabolism of human adipose tissue. I. Comparison between in vitro effects of noradrenaline, adrenaline and theophylline on lipolysis in omental adipose tissue. Acta Med. Scand. 186:241-246.

10. James, R. C., T. W. Burns, and R. Chase. 1971. Lipolysis in human adipose tissue cells: influence of donor factors. J. Lab. Clin. Med. 77:254-266.

11. Lakatta, E. G., G. Gerstenblith, C. S. Angell, N. W. Schóck, and M. L. Weisfeldt. 1975. Diminished inotropic response of aged myocardium to catecholamines. Circ. Res. 36:262-269.

12. Schocken, D. D., and G. S. Roth. 1977. Reduced beta-adrenergic receptor concentrations in ageing man. Nature (Lond.). 267:856858.

13. Guidicelli, Y., and R. Pecquery. 1978. Beta-adrenergic receptors and catecholamine-sensitive adenylate cyclase in rat fat cell membranes: influence of growth, cell size and aging. Eur. J. Biochem. 90:413-419.

14. Vestal, R. E., A. J. J. Wood, and D. G. Shand. 1979. Reduced beta-adrenoceptor sensitivity in the elderly. Clin. Pharmacol. Ther. 26:181-185.

15. Abrass, I. B., and P. J. Scarpace. 1982. Catalytic unit of adenylate cyclase: reduced activity in aged human lymphocytes. J. Clin. Endocrinol. Metab. 55:1026-1028.

16. Feldman, R. D., L. E. Limbird, J. Nadeau, D. Robertson, and A. J. J. Wood. 1984. Alterations in leukocyte beta-receptor affinity with aging. N. Engl. J. Med. 310:815-819.

17. Dillon, N., S. Chung, J. Kelly, and K. O'Malley. 1984. Age and beta adrenoceptor-mediated function. Clin. Pharmacol. Ther. 27:769-772.

18. Kelly, J., and K. O'Malley. 1984. Adrenoceptor function and aging. Clin. Sci. 66:509-515.

19. Krall, J. E., M. Connely, R. Weisbart, and M. L. Tuck. 1981. Age-related elevation of plasma catecholamine concentration and reduced responsiveness of lymphocyte adenylate cyclase. J. Clin. Endocrinol. Metab. 52:863-867.

20. Abrass, I. B., and P. J. Scarpace. 1981. Human lymphocyte beta-adrenergic receptors are unaltered with age. J. Gerontol. 36:298301.

21. Doyle, V., K. O'Malley, and J. G. Kelly. 1982. Human lymphocyte beta-adrenoceptor density in relation to age and hypertension. J. Cardiovasc. Pharmacol. 4:738-740.

22. Fain, J. N., and J. A. Garcia-Sáinz. 1983. Adrenergic regulation of adipocyte metabolism. J. Lipid Res. 24:945-966.

23. Arner, P., O. Arner, and J. Östman. 1973. The effect of local anaesthetic agents on lipolysis by human adipose tissue. Life Sci. 13:161-169.

24. Wahrenberg, H., F. Lönnqvist, P. Engfeldt, and P. Arner. 1989. Abnormal action of catecholamines on lipolysis in adipocytes of type I diabetic patients treated with insulin. Diabetes. 38:524-533.

25. Arner, P., J. Bolinder, J. Hellmér, and P. Engfeldt. 1986. Studies on human fat cell metabolism in small adipose tissue samples. In Methods in Diabetes Research. W. L. Clarke, J. Larner, and S. L. Pohl, editors. Vol. 2. John Wiley and Sons Inc., New York. 234-258.

26. Wahrenberg, H., F. Lönnqvist, and P. Arner. 1989. Mecha- 
nisms underlying regional differences in lipolysis in human adipose tissue. J. Clin. Invest. 84:458-467.

27. Munson, P. J., and D. A. Rodbard. 1980. A versatile computerized approach for characterization of ligand binding systems. Anal. Biochem. 107:220-239.

28. Hellmér, J., P. Arner, and A. Lundin. 1989. Automatic luminometric kinetic assay of glycerol for lipolysis studies. Anal. Biochem. 177:132-137.

29. Cooper, B., and R. I. Gregerman. 1976. Hormone-sensitive fat cell adenylate cyclase in the rat. Influences of growth, cell size and aging. J. Clin. Invest. 57:161-168.

30. Forn, J., P. S. Schonhofer, I. F. Skidmore, and G. Krishna. 1970. Effect of aging on the adenyl cyclase and phosphodiesterase activity of isolated fat cells of rat. Biochim. Biophys. Acta. 208:304309.

31. Hoffman, B. B., H. Chang, Z. Farahbakhsh, and G. Reaven. 1984. Inhibition of lipolysis by adenosine is potentiated with age. $J$. Clin. Invest. 74:1750-1755.

32. Hoffman, B. B., H. Chang, and G. M. Reaven. 1987. Stimulation and inhibition of lipolysis in isolated rat adipocytes; evidence for age-related changes in responses to forskolin and $\mathrm{PGE}_{1}$. Horm. Metab. Res. 19:358-360.
33. Dax, E. M., J. S. Partilla, and R. I. Gregerman. 1981. Mechanisms of the age-related decrease of epinephrine-stimulated lipolysis in isolated rat adipocytes; beta-adrenergic receptor binding, adenylate cyclase activity, and cyclic AMP accumulation. J. Lipid Res. 22:934943.

34. Marcus, C., B. Karpe, P. Bolme, T. Sonnenfeld, and P. Arner. 1987. Changes in catecholamine-induced lipolysis in isolated human fat cells during the first year of life. J. Clin. Invest. 79:1812-1818.

35. Marcus, C., H. Ehrén, P. Bolme, and P. Arner. 1988. Regulation of lipolysis during the neonatal period: Importance of thyrotropin. J. Clin. Invest. 82:1793-1797.

36. Bülow, J., and J. Madsen. 1986. Regulation of fatty acid mobilization from adipose tissue during exercise. Scand. J. Sports Sci. 8:19-26.

37. Burns, T. W., C. W. Gehrke, M. J. Angian, and P. E. Langley. 1963. Effect of insulin on plasma free fatty acids of normal subjects. $J$. Lab. Clin. Med. 62:646-653.

38. Wahrenberg, H., P. Engfeldt, J. Bolinder, and P. Arner. 1987. Acute adaption in adrenergic control of lipolysis during physical exercise in man. Am. J. Physiol. 253:E383-E390.

39. Bolinder, J., J. Östman, and P. Arner. 1984. Influence of aging on insulin receptor binding and metabolic effects of insulin in human adipose tissue. Diabetes. 32:959-964. 